\title{
Physical activity: the forgotten tool for type 2 diabetes management
}

\section{Sheri R. Colberg*}

Human Movement Sciences Department, Old Dominion University, Norfolk, VA, USA

\section{Edited by:}

Margarita De Veciana, Eastern Virginia

Medical School, USA

\section{Reviewed by:}

Kay Waud, Eastern Virginia Medical School, USA

Ann Virae Collie, Community Health

Systems, USA

${ }^{*}$ Correspondence:

Sheri R. Colberg, Human Movement Sciences Department, Old Dominion

University, Student Recreation Center, Room 1006B, Norfolk, VA 23529,

USA. e-mail: scolberg@odu.edu
Individuals who are currently sedentary, unfit, or overweight can benefit metabolically from simply taking breaks from sitting. Since avoidance of sedentary behavior appears to have a large impact on glycemic management, all individuals with type 2 diabetes should be encouraged to minimally engage in greater daily movement to better manage their diabetes and body weight. In addition, engaging in physical activity of any intensity (including lowintensity ones) likely positively impacts insulin action and blood glucose control acutely. Moreover, as long as total caloric expenditure during exercise is matched (i.e., total exercise dose), daily exercise may be done every other day instead with the same glycemic results, although at least 150 min of weekly physical activity is recommended. Both aerobic and resistance training are important for individuals with diabetes, and ideally a program that combines the two types of training should be undertaken to achieve maximal glycemic and other benefits. Once individuals have successfully implemented more daily movement into their lifestyle, they will be more likely to participate in structured forms of physical activity to gain additional benefits. All clinicians working with individuals with either type 2 diabetes or prediabetes should consider incorporating these suggestions into care plans to improve their patients' glycemic management.

Keywords: type 2 diabetes, physical activity, exercise, sedentary behavior, physical inactivity, glycemic control

\section{INTRODUCTION}

For individuals who are currently sedentary, unfit, or overweight, the research is now compellingly clear that they can benefit metabolically from simply taking breaks from sitting regardless of whether they undertake other forms of physical activity (Healy et al., 2008; Cooper et al., 2012; Dunstan et al., 2012). Of course, they can additionally benefit from engaging in other types of activity (Boulé et al., 2001; Irvine and Taylor, 2009; Dube et al., 2012). The treatment goal for individuals with type 2 diabetes is to achieve and maintain optimal blood glucose, lipid, and blood pressure levels to prevent or delay chronic complications of diabetes (American Diabetes Association, 2012). Consequently, the purpose of this review is to reinforce how sedentary individuals with type 2 diabetes can greatly improve their metabolic health by taking small steps away from sedentary behavior toward greater physical activity participation.

\section{TAKING BREAKS IN SEDENTARY TIME AND DOING MORE DAILY MOVEMENT}

"Physical activity" includes any bodily movement that substantially increases energy expenditure, whereas "exercise" is the subset of planned, structured, and repetitive movements done to develop or maintain physical fitness, which includes cardiovascular, strength, and flexibility training options (Haskell et al., 2007; Nelson etal., 2007). Individuals with diabetes are frequently deconditioned and live a sedentary lifestyle (Church et al., 2005; Zhao et al., 2008; Larose et al., 2011). Therefore, the first major step in becoming regularly physically active is incorporation of more activities of daily living and other unstructured physical activity into their lifestyles (Levine et al., 2005; Johannsen et al., 2008).

Standing up and moving around more can by themselves lower metabolic risk, and health benefits result from concurrently reducing total time engaged in sedentary pursuits and interspersing frequent, short bouts of standing and physical activity between periods of sedentary activity, even in physically active adults (Garber et al., 2011; Dunstan et al., 2012). Making small changes in daily activity levels, such as taking a 5-min walking break every hour, also likely benefits weight management. An individual will theoretically expend an additional 24,59, or $132 \mathrm{kcal}$ during an 8 $\mathrm{h}$ workday by walking around at a normal, self-selected pace for 1 , 2 , or 5 min every hour, respectively, compared with sitting for that whole time (Swartz et al., 2011). Even modest amounts of exercise in the absence of weight loss positively affect markers of glucose and fat metabolism in previously sedentary adults (Duncan et al., 2003). Taking breaks from sedentary time is a potential way to lose weight and prevent weight gain, and it may assist in preventing the onset of type 2 diabetes.

In middle-aged adults without diabetes, sedentary time predicts higher levels of fasting insulin independent of the amount of time spent doing moderate- and vigorous-intensity activity levels (Helmerhorst et al., 2009). For anyone with diabetes, inclusion of more daily, unstructured physical activity is likely to bestow even greater glycemic benefits. Participants in the Australian Diabetes, Obesity, and Lifestyle study wore accelerometers to measure sedentary time for seven consecutive days. Independent of total sedentary time and moderate- to vigorous-intensity activity, taking more frequent breaks in sedentary time was beneficially 
associated with waist circumference, body mass index, triglyceride levels, and 2-h postmeal plasma glucose, highlighting the importance of avoiding prolonged uninterrupted periods of sedentary time (Healy et al., 2008). Frequent breaks from sitting may also assist in controlling postprandial spikes prevalent throughout the day in many individuals with type 2 diabetes, even in those with a glycated hemoglobin (HbA1c) level well below 7.0\% (van Dijk et al., 2011).

In newly diagnosed adults with type 2 diabetes (ages 30-80 years), more time spent in sedentary pursuits has been associated with a larger waist circumference (Cooper et al., 2012), likely reflective of a greater amount of deleterious visceral fat (Amati et al., 2012). However, non-exercise activity thermogenesis (i.e., activities of daily living) can create a large daily caloric deficit to prevent excessive weight gain, which can facilitate body weight and glycemic management (Levine et al., 2005, 2008). Even standing counts as unstructured activity. Obese individuals sit for about $2.5 \mathrm{~h}$ more and walk 3.5 miles less per day than their lean counterparts (Levine et al., 2005). Furthermore, most of the activity done by lean individuals consists of walks of short-duration (<15 min) and low-velocity ( $1 \mathrm{mile} / \mathrm{h})$. How long individuals sit each day or include movement during periods of prolonged inactivity is critical to metabolic health and diabetes management.

\section{HOW DOES PHYSICAL ACTIVITY ACUTELY AFFECT GLYCEMIA?}

Previously, the assumption was that aging underlies the reductions in insulin action common in the elderly; however, insulin resistance may not be a normal characteristic of aging, but rather associated with obesity and physical inactivity (Amati et al., 2009). Engaging in almost any type of physical activity facilitates glucose uptake, improves insulin sensitivity, and aids in glucose homeostasis by enhancing resting insulin action and lowering blood glucose levels for 2-72 h after the last bout of activity, depending on the exercise duration, intensity, and subsequent food intake (King et al., 1995; Boulé et al., 2001, 2005; O'Gorman et al., 2006). Exercised muscles take up more blood glucose during the ensuing rest period with the contraction-mediated pathway persisting for several hours (Ivy and Holloszy, 1981; Garetto et al., 1984) and insulin-mediated uptake for longer (Richter et al., 1982; Cartee et al., 1989; King et al., 1995; Bajpeyi et al., 2009). In adults with type 2 diabetes who exercise moderately, muscular uptake of blood glucose use usually exceeds hepatic glucose production, and blood glucose levels decline during the activity (Minuk et al., 1981). Plasma insulin levels concomitantly fall, making the risk of exercise-induced hypoglycemia low as long as the individual is not taking insulin or insulin secretagogues (Koivisto and Defronzo, 1984). Muscular contractions increase blood glucose uptake to supplement muscular glycogen use (Ploug et al., 1984; Richter et al., 1985). Since this uptake pathway is contraction-induced and distinct from the one triggered by insulin (Khayat et al., 2002), glucose uptake into working muscle is normal even when insulinmediated uptake is impaired (Colberg et al., 1996; Zierath et al., 1996; Braun et al., 2004).

Daily movement by itself apparently has a large impact on how well the body handles carbohydrate intake. In a recent study, healthy normally active adults cut their physical activity levels (as monitored with daily steps) from over 10,000 a day to less than 5,000, which is considered a sedentary level (Mikus et al., 2012). The result over a 3-day period was that despite their release extra insulin in response to a glucose load, postprandial glucose spikes increased significantly and progressively over the 3 days, which reinforces the importance of daily physical activity as a mediator of glycemic control even without diabetes. In older individuals with type 2 diabetes, simply undertaking $20 \mathrm{~min}$ of self-paced walking after the dinner meal has been shown to be effective at lowering its glycemic impact compared with pre-meal walking or no exercise (Colberg et al., 2009).

Moreover, a single bout of moderate aerobic exercise can have a more lasting effect on diabetes management than previously thought. In a recent study, individuals with impaired glucose tolerance or type 2 diabetes engaged in a single session of either $30 \mathrm{~min}$ of moderate aerobic exercise or $45 \mathrm{~min}$ of moderate resistance training (van Dijk et al., 2012a). A single bout of either exercise substantially reduced the prevalence of hyperglycemia (blood glucose levels $>10 \mathrm{mmol} / \mathrm{L}$ ) for the following $24 \mathrm{~h}$ using continuous glucose monitoring. It also appears that total exercise need not be completed in a single session to be effective since in elderly men with type 2 diabetes, moderate- to high-intensity training performed more frequently (done as three, 10-min sessions daily) resulted in more beneficial effects on glycemic control than doing a single, 30-min session, even though cardiorespiratory fitness increased similarly (Eriksen et al., 2007).

\section{DOES EXERCISE HAVE TO BE INTENSE?}

Blood glucose decreases during any physical activity are related to the intensity and duration of the exercise, pre-exercise control, and state of physical training (Colberg et al., 1996; Boulé et al., 2001, 2005; Sigal et al., 2007). Although prior physical activity of any intensity generally enhances uptake of circulating glucose for glycogen synthesis (Christ-Roberts et al., 2003; Galbo et al., 2007), and stimulates fat oxidation and storage in muscle (Duncan et al., 2003; Goodpaster et al., 2003; Boon et al., 2007), more prolonged or intense activity usually enhances acute insulin action for longer (Braun et al., 1995; Larsen et al., 1999; Houmard et al., 2004; Evans et al., 2005; Sigal et al., 2007; Bajpeyi et al., 2009). During brief, intense aerobic exercise, plasma catecholamine levels rise markedly, driving a major increase in blood glucose production (Marliss and Vranic, 2002). As a consequence, hyperglycemia can result and persist for up to $1-2 \mathrm{~h}$, likely because plasma catecholamine levels and glucose production do not return to normal immediately with cessation of the intense activity (Marliss and Vranic, 2002).

Recently, low-volume, high-intensity training (HIT) was shown to rapidly improve glucose control and induce adaptations in skeletal muscle that are linked to improved metabolic health in adults with type 2 diabetes (Little et al., 2011). In that study, participants undertook 2 weeks of thrice weekly exercise that consisted of ten 60 -s sessions separated by $1 \mathrm{~min}$ of rest done at $90 \%$ of maximal heart rate. Training reduced blood glucose by $13 \%$ over the 24-h period following training, as well as postprandial glucose spikes for several days afterwards. However, given the intensity of such training, each individual's fitness level and cardiovascular 
risk factors should be carefully considered before HIT is prescribed.

Conversely, physical activity need not be intense to be beneficial. Acute improvements in insulin sensitivity in women with type 2 diabetes have been found for equivalent energy expenditures whether they engaged in low-intensity or high-intensity walking (Braun et al., 1995). Reduction in coronary risk factors and other benefits can be obtained by incorporating frequent bouts of moderate-intensity activity on most days of the week even if not a traditional, structured one (McBride et al., 2008; Loimaala et al., 2009). Moreover, even light-intensity physical activity is associated with blood glucose reductions, whereas sedentary time is unfavorably associated with increased levels (Healy et al., 2007). Adults with type 2 diabetes who performed an isoenergetic bout of endurance-type exercise for $60 \mathrm{~min}$ at a low intensity or $30 \mathrm{~min}$ at a high intensity reduced their prevalence of hyperglycemia by 50 and $19 \%$, respectively, for $24 \mathrm{~h}$ afterwards (Manders etal., 2010). Therefore, a single bout of low-intensity work may actually be more effective at lowering the prevalence of hyperglycemia throughout the subsequent 24 -h period than high-intensity work. Others have confirmed that when matched for energy cost, prolonged continuous low- to moderate-intensity endurance-type exercise and moderate- to high-intensity training done 3 days a week are equally effective in lowering $\mathrm{HbAlc}$ and increasing whole body and skeletal muscle oxidative capacity in obese individuals with type 2 diabetes (Hansen et al., 2009).

Engaging in low-intensity activities likely bestows other positive effects, including preventing some of the potential decline in cognition commonly found in older individuals with type 2 diabetes (Colberg et al., 2008). Even simple, low-intensity balance training done for 6 weeks by older participants with type 2 diabetes substantially lowers their falls risk (Morrison et al., 2010, 2012), which may promote further participation in all levels of physical activity by removing their fear of falling (Borer, 2005; Zijlstra et al., 2007).

\section{SHOULD EXERCISE BE DAILY OR LESS FREQUENT?}

Although the common belief is that doing daily exercise is better, but that may not be necessary. A graded dose-response relationship appears to exist between the aerobic exercise training dose (a product of exercise intensity, duration, and frequency) and improvements in insulin sensitivity. Exercise intensity has been shown to be significantly related to improvements in insulin action, while frequency may not be, at least in 55 healthy adults undergoing 16 weeks of supervised endurance training (three to five sessions lasting $45 \mathrm{~min} /$ week, with three sessions supervised; Dube et al., 2012). Others have shown that engaging in structured exercise training of more than $150 \mathrm{~min} /$ week results in greater glycemic benefits, thus the total exercise dose may be important (Umpierre et al., 2011). Engaging in 170 min of exercise per week has been shown to improve insulin sensitivity more substantially than $115 \mathrm{~min}$, regardless of exercise intensity and volume, suggesting that total exercise duration should thus be considered when designing training programs to improve insulin action (Houmard et al., 2004).

Aerobic exercise is recommended at least 3 days/week with no more than two consecutive days between bouts of activity due to the short-lived nature of improvements in insulin action (King etal., 1995; Boulé et al., 2005). Most exercise interventions in adults with type 2 diabetes have used a frequency of three times per week (Boulé et al., 2001; Snowling and Hopkins, 2006; Thomas et al., 2006; Sigal et al., 2007), but current guidelines for adults generally recommend five sessions of moderate activity (Haskell et al., 2007; Nelson et al., 2007; Physical Activity Guidelines Advisory Committee, 2008). However, in a recent study, when adults with type 2 diabetes either did no exercise or engaged in $60 \mathrm{~min}$ of moderate cycling exercise distributed either as a single session performed every other day or as $30 \mathrm{~min}$ of exercise performed daily and their blood glucose was monitored continuously for $48 \mathrm{~h}$, their prevalence of hyperglycemia was reduced from $32 \%$ of that period following no exercise to $24 \%$ over $48 \mathrm{~h}$ following daily cycling or following cycling done every other day (van Dijk et al., 2012b). Thus, it appears that as long as total caloric expenditure during exercise is matched, daily exercise can be done every other day instead and have the same beneficial glycemic results.

\section{IS RESISTANCE TRAINING NECESSARY?}

In older individuals who are overweight or obese, the loss of muscle mass combined with fat weight gain can result in sarcopenic obesity and decreased mobility (Baumgartner, 2000; Baumgartner et al., 2004). Resistance training has been shown to improve musculoskeletal health, enhance the ability to perform activities of daily living, and lower the risk of injury (including from accidental falls) and descent into frailty (Willey and Singh, 2003; Haskell et al., 2007; Nelson et al., 2007; Garber et al., 2011). In fact, properly designed resistance programs may improve cardiovascular function, glucose tolerance, strength, and body composition, allowing older adults to remain more independent and selfsufficient as they age (Bemben et al., 2000; Castaneda et al., 2002; Dunstan etal., 2002; Cornelissen and Fagard, 2005; Daly et al., 2005; Cohen et al., 2008; American College of Sports Medicine, 2009; Church et al., 2010).

Resistance training has additional metabolic benefits. It can improve glycemic control, likely even more so than aerobic training (Ishii et al., 1998; Poehlman et al., 2000; Castaneda et al., 2002; Vincent et al., 2002; Ibanez et al., 2005; Snowling and Hopkins, 2006). Despite the fact that intense resistance exercise can acutely raise blood glucose levels ensuing from an exaggerated counter regulatory hormonal response (Kreisman et al., 2003), regular resistance work improves overall glycemic control and insulin sensitivity by increasing levels of muscle GLUT4, insulin receptors, protein kinase B, glycogen synthase, and glycogen synthase total activity following acute training (Holten et al., 2004). In older men with new-onset diabetes, 16 weeks of twice-weekly progressive resistance training resulted in a $46 \%$ increase in insulin sensitivity, $7 \%$ reduction in fasting blood glucose, and loss of visceral fat, all while consuming a $15.5 \%$ average higher calorie intake (Ibanez et al., 2005). In fact, when combined with moderate weight loss, resistance training was more effective for improving overall glycemic control than moderate weight loss alone and prevented muscle mass loss (Dunstan et al., 2002).

Much of the observed enhancement in insulin action with resistance exercise may be related to greater muscle mass, which 
can result from a variety of different training intensities (Bemben et al., 2000; Castaneda et al., 2002; Willey and Singh, 2003). Engaging in 16 weeks of progressive resistance training not only reduces $\mathrm{HbA1c}$ levels significantly in adults with type 2 diabetes, but also increases muscle glycogen stores and allows $72 \%$ of participants to reduce prescribed medication doses (Castaneda et al., 2002). Acute resistance exercise sessions with either light or moderate intensities are effective for controlling blood glucose levels (Moreira et al., 2011); however, home-based progressive resistance training following supervised training is less effective for maintaining glycemic control than gymnasium-based work. Improvements in muscle strength and mass can be similar, but reduced adherence and exercise training volume and intensity may impede its glycemic impact (Dunstan et al., 2005).

\section{WHAT ABOUT COMBINED AEROBIC AND RESISTANCE TRAINING?}

Finally, in almost all studies undertaken to date that have compared combined training with either aerobic or resistance training alone, the total duration of exercise and caloric expenditure have been greater during combined training (Cuff et al., 2003; Sigal et al., 2007; Marcus et al., 2008), and both types of training have been undertaken together on the same days. However, a recent study examined the effects of an equal caloric expenditure among combined and separate aerobic and resistance training groups (Church etal., 2010). In that study, adults with type 2 diabetes did resistance training alone 3 days a week, aerobic exercise (expending $12 \mathrm{kcal} / \mathrm{kg} /$ week), or combined aerobic and resistance training. Surprisingly, only those doing combined training

\section{REFERENCES}

Amati, F., Dube, J. J., Coen, P. M., Stefanovic-Racic, M., Toledo, F. G., and Goodpaster, B. H. (2009). Physical inactivity and obesity underlie the insulin resistance of aging. Diabetes Care 32, 1547-1549.

Amati, F., Pennant, M., Azuma, K., Dube, J. J., Toledo, F. G., Rossi, A. P., Kelley, D. E., and Goodpaster, B. H. (2012). Lower thigh subcutaneous and higher visceral abdominal adipose tissue content both contribute to insulin resistance. Obesity (Silver Spring) 20, 1115-1117.

American College of Sports Medicine. (2009). American College of Sports Medicine position stand. Progression models in resistance training for healthy adults. Med. Sci. Sports Exerc. 41, 687-708.

American Diabetes Association. (2012). Standards of medical care in diabetes 2012. Diabetes Care 35, S11-S63.

Bajpeyi, S., Tanner, C. J., Slentz, C. A., Duscha, B. D., Mccartney, J. S., Hickner, R. C., Kraus, W. E., and Houmard, J. A. (2009). Effect of exercise intensity and volume on persistence of insulin sensitivity during training cessation. J. Appl. Physiol. 106, 1079-1085.
Baumgartner, R. N. (2000). Body composition in healthy aging. Ann. N.Y. Acad. Sci. 904, 437-448.

Baumgartner, R. N., Wayne, S. J., Waters, D. L., Janssen, I., Gallagher, D., and Morley, J. E. (2004). Sarcopenic obesity predicts instrumental activities of daily living disability in the elderly. Obes. Res. 12, 1995-2004.

Bemben, D. A., Fetters, N. L., Bemben, M. G., Nabavi, N., and Koh, E. T. (2000). Musculoskeletal responses to high- and low-intensity resistance training in early postmenopausal women. Med. Sci. Sports Exerc. 32, 1949-1957.

Boon, H., Blaak, E. E., Saris, W. H., Keizer, H. A., Wagenmakers, A. J., and Van Loon, L. J. (2007). Substrate source utilisation in long-term diagnosed type 2 diabetes patients at rest, and during exercise and subsequent recovery. Diabetologia 50, 103-112.

Borer, K. T. (2005). Physical activity in the prevention and amelioration of osteoporosis in women: interaction of mechanical, hormonal and dietary factors. Sports Med. 35, 779-830.

Boulé, N. G., Haddad, E., Kenny, G. P., Wells, G. A., and Sigal, R. J. (2001). Effects of exercise on glycemic control

(with twice-weekly resistance work) improved their HbAlc levels significantly.

In a recent meta-analysis, aerobic, resistance, and combined exercise training were found to be associated with $\mathrm{HbAlc}$ reductions of $0.67 \%$ following 12 or more weeks of training (Umpierre et al., 2011). Structured exercise exceeding $150 \mathrm{~min} /$ week, however, was associated with greater glycemic benefit $(0.89 \%$ lower HbA1c) than 150 min or less $(0.36 \%$ reduction), although any type of training caused greater declines in glycemic levels than physical activity advice alone. Unfortunately, no studies have yet investigated whether daily, but alternating, training would be more effective, and the blood glucose impact of various isocaloric combinations of training programs remains to be fully studied.

\section{CONCLUSION}

Since simply avoiding sedentary behavior appears to have a large impact on glycemic management, individuals with type 2 diabetes should be encouraged to minimally engage in frequent daily movement to better manage their diabetes and body weight. While daily movement is not as effective as most structured exercise programs in increasing fitness levels, it is important for expending extra calories, breaking up sitting time, and building a fitness base in sedentary individuals. Once increased daily movement is implemented, individuals will likely feel more confident, ready, and able to participate in structured forms of physical activity, including both aerobic and resistance training of varying intensities, which can greatly enhance their health and diabetes management.

and body mass in type 2 diabetes mellitus: a meta-analysis of controlled clinical trials. JAMA 286, 1218-1227.

Boulé, N. G., Weisnagel, S. J., Lakka, T. A., Tremblay, A., Bergman, R. N., Rankinen, T., Leon, A. S., Skinner, J. S., Wilmore, J. H., Rao, D. C., and Bouchard, C. (2005). Effects of exercise training on glucose homeostasis: the HERITAGE Family Study. Diabetes Care 28, 108-114.

Braun, B., Sharoff, C., Chipkin, S. R., and Beaudoin, F. (2004). Effects of insulin resistance on substrate utilization during exercise in overweight women. J. Appl. Physiol. 97, 991-997.

Braun, B., Zimmermann, M. B., and Kretchmer, N. (1995). Effects of exercise intensity on insulin sensitivity in women with non-insulin-dependent diabetes mellitus. J. Appl. Physiol. 78, 300-306.

Cartee, G. D., Young, D. A., Sleeper, M. D., Zierath, J., Wallberg-Henriksson, H., and Holloszy, J. O. (1989). Prolonged increase in insulin-stimulated glucose transport in muscle after exercise. Am. J. Physiol. 256, E494-E499.

Castaneda, C., Layne, J. E., MunozOrians, L., Gordon, P. L., Walsmith, J.,
Foldvari, M., Roubenoff, R., Tucker, K. L., and Nelson, M. E. (2002). A randomized controlled trial of resistance exercise training to improve glycemic control in older adults with type 2 diabetes. Diabetes Care 25, 2335-2341.

Christ-Roberts, C. Y., Pratipanawatr, T., Pratipanawatr, W., Berria, R., Belfort, R., and Mandarino, L. J. (2003). Increased insulin receptor signaling and glycogen synthase activity contribute to the synergistic effect of exercise on insulin action. J. Appl. Physiol. 95, 2519-2529.

Church, T. S., Blair, S. N., Cocreham, S., Johannsen, N., Johnson, W., Kramer, K., Mikus, C. R., Myers, V., Nauta, M., Rodarte, R. Q., Sparks, L., Thompson, A., and Earnest, C. P. (2010). Effects of aerobic and resistance training on hemoglobin Alc levels in patients with type 2 diabetes: a randomized controlled trial. JAMA 304, 2253-2262.

Church, T. S., Lamonte, M. J., Barlow, C. E., and Blair, S. N. (2005). Cardiorespiratory fitness and body mass index as predictors of cardiovascular disease mortality among men with diabetes. Arch. Intern. Med.165, 2114-2120. 
Cohen, N. D., Dunstan, D. W., Robinson, C., Vulikh, E., Zimmet, P. Z., and Shaw, J. E. (2008). Improved endothelial function following a 14month resistance exercise training program in adults with type 2 diabetes. Diabetes Res. Clin. Pract. 79, 405-411.

Colberg, S. R., Hagberg, J. M., Mccole, S. D., Zmuda, J. M., Thompson, P. D., and Kelley, D. E. (1996). Utilization of glycogen but not plasma glucose is reduced in individuals with NIDDM during mild-intensity exercise. J. Appl. Physiol. 81, 2027-2033.

Colberg, S. R., Somma, C. T., and Sechrist, S. R. (2008). Physical activity participation may offset some of the negative impact of diabetes on cognitive function. J. Am. Med. Dir. Assoc. 9, 434-438.

Colberg, S. R., Zarrabi, L., Bennington, L., Nakave, A., Thomas Somma, C., Swain, D. P., and Sechrist, S. R. (2009). Postprandial walking is better for lowering the glycemic effect of dinner than pre-dinner exercise in type 2 diabetic individuals. J. Am. Med. Dir. Assoc. 10, 394-397.

Cooper, A. R., Sebire, S., Montgomery, A. A., Peters, T. J., Sharp, D. J., Jackson, N., Fitzsimons, K., Dayan, C. M., and Andrews, R. C. (2012). Sedentary time, breaks in sedentary time and metabolic variables in people with newly diagnosed type 2 diabetes. Diabetologia 55, 589-599.

Cornelissen, V. A., and Fagard, R. H. (2005). Effect of resistance training on resting blood pressure: a metaanalysis of randomized controlled trials. J. Hypertens. 23, 251-259.

Cuff, D. J., Meneilly, G. S., Martin, A., Ignaszewski, A., Tildesley, H. D., and Frohlich, J. J. (2003). Effective exercise modality to reduce insulin resistance in women with type 2 diabetes. Diabetes Care 26, 2977-2982.

Daly, R. M., Dunstan, D. W., Owen, N., Jolley, D., Shaw, J. E., and Zimmet, P. Z. (2005). Does highintensity resistance training maintain bone mass during moderate weight loss in older overweight adults with type 2 diabetes? Osteoporos Int. 16, 1703-1712.

Dube, J. J., Fleishman, K., Rousson, V., Goodpaster, B. H., and Amati, F. (2012). Exercise dose and insulin sensitivity: relevance for diabetes prevention. Med. Sci. Sports Exerc. 44, 793-779.

Duncan, G. E., Perri, M. G., Theriaque, D. W., Hutson, A. D., Eckel, R. H., and Stacpoole, P. W. (2003). Exercise training, without weight loss, increases insulin sensitivity and postheparin plasma lipase activity in previously sedentary adults. Diabetes Care 26, 557-562.

Dunstan, D. W., Daly, R. M., Owen, N., Jolley, D., De Courten, M., Shaw, J., and Zimmet, P. (2002). Highintensity resistance training improves glycemic control in older patients with type 2 diabetes. Diabetes Care 25, 1729-1736.

Dunstan, D. W., Daly, R. M., Owen, N., Jolley, D., Vulikh, E., Shaw, J., and Zimmet, P. (2005). Home-based resistance training is not sufficient to maintain improved glycemic control following supervised training in older individuals with type 2 diabetes. Diabetes Care 28, 3-9.

Dunstan, D. W., Kingwell, B. A., Larsen, R., Healy, G. N., Cerin, E., Hamilton, M. T., Shaw, J. E., Bertovic, D. A., Zimmet, P. Z., Salmon, J., and Owen, N. (2012). Breaking up prolonged sitting reduces postprandial glucose and insulin responses. Diabetes Care 35, 976-983.

Eriksen, L., Dahl-Petersen, I., Haugaard, S. B., and Dela, F. (2007). Comparison of the effect of multiple shortduration with single long-duration exercise sessions on glucose homeostasis in type 2 diabetes mellitus. Diabetologia 50, 2245-2253.

Evans, E. M., Racette, S. B., Peterson, L. R., Villareal, D. T., Greiwe, J. S., and Holloszy, J. O. (2005). Aerobic power and insulin action improve in response to endurance exercise training in healthy 77-87 yr olds. J. Appl. Physiol. 98, 40-45.

Galbo, H., Tobin, L., and Van Loon, L. J. (2007). Responses to acute exercise in type 2 diabetes, with an emphasis on metabolism and interaction with oral hypoglycemic agents and food intake. Appl. Physiol. Nutr. Metab. 32, 567-575.

Garber, C. E., Blissmer, B., Deschenes, M. R., Franklin, B. A., Lamonte, M. J., Lee, I. M., Nieman, D. C., Swain, D. P., and American College of Sports Medicine. (2011). American College of Sports Medicine position stand. Quantity and quality of exercise for developing and maintaining cardiorespiratory, musculoskeletal, and neuromotor fitness in apparently healthy adults: guidance for prescribing exercise. Med. Sci. Sports Exerc. 43, 1334-1359.

Garetto, L. P., Richter, E. A., Goodman, M. N., and Ruderman, N. B. (1984). Enhanced muscle glucose metabolism after exercise in the rat: the two phases. Am. J. Physiol. 246, E471-E475.

Goodpaster, B. H., Katsiaras, A., and Kelley, D. E. (2003). Enhanced fat oxidation through physical activity is associated with improvements in insulin sensitivity in obesity. Diabetes 52, 2191-2197.

Hansen, D., Dendale, P., Jonkers, R. A., Beelen, M., Manders, R. J., Corluy, L., Mullens, A., Berger, J., Meeusen, R., and Van Loon, L. J. (2009). Continuous low- to moderate-intensity exercise training is as effective as moderate- to high-intensity exercise training at lowering blood $\mathrm{HbA}(1 \mathrm{c})$ in obese type 2 diabetes patients. Diabetologia 52, 1789-1797.

Haskell, W. L., Lee, I. M., Pate, R. R., Powell, K. E., Blair, S. N., Franklin, B. A., Macera, C. A., Heath, G. W., Thompson, P. D., and Bauman, A. (2007). Physical activity and public health: updated recommendation for adults from the American College of Sports Medicine and the American Heart Association. Med. Sci. Sports Exerc. 39, 1423-1434.

Healy, G. N., Dunstan, D. W., Salmon, J., Cerin, E., Shaw, J. E., Zimmet, P. Z., and Owen, N. (2007). Objectively measured light-intensity physical activity is independently associated with 2-h plasma glucose. Diabetes Care 30, 1384-1389.

Healy, G. N., Dunstan, D. W., Salmon, J., Cerin, E., Shaw, J. E., Zimmet, P. Z., and Owen, N. (2008). Breaks in sedentary time: beneficial associations with metabolic risk. Diabetes Care 31, 661-666.

Helmerhorst, H. J., Wijndaele, K., Brage, S., Wareham, N. J., and Ekelund, U. (2009). Objectively measured sedentary time may predict insulin resistance independent of moderate- and vigorous-intensity physical activity. Diabetes 58, 1776-1779.

Holten, M. K., Zacho, M., Gaster, M., Juel, C., Wojtaszewski, J. F., and Dela, F. (2004). Strength training increases insulin-mediated glucose uptake, GLUT4 content, and insulin signaling in skeletal muscle in patients with type 2 diabetes. Diabetes 53, 294-305.

Houmard, J. A., Tanner, C. J., Slentz, C. A., Duscha, B. D., Mccartney, J.S., and Kraus, W. E. (2004). Effect of the volume and intensity of exercise training on insulin sensitivity. J. Appl. Physiol. 96, 101-106.

Ibanez, J., Izquierdo, M., Arguelles, I., Forga, L., Larrion, J. L., GarciaUnciti, M., Idoate, F., and Gorostiaga, E. M. (2005). Twice-weekly progressive resistance training decreases abdominal fat and improves insulin sensitivity in older men with type 2 diabetes. Diabetes Care 28, 662-667.

Irvine, C., and Taylor, N. F. (2009). Progressive resistance exercise improves glycaemic control in people with type 2 diabetes mellitus: a systematic review. Aust. J. Physiother. 55, 237-246.

Ishii, T., Yamakita, T., Sato, T., Tanaka, S., and Fujii, S. (1998). Resistance training improves insulin sensitivity in NIDDM subjects without altering maximal oxygen uptake. Diabetes Care 21, 1353-1355.

Ivy, J. L., and Holloszy, J. O. (1981). Persistent increase in glucose uptake by rat skeletal muscle following exercise. Am. J. Physiol. 241, C200-C203.

Johannsen, D. L., Welk, G. J., Sharp, R. L., and Flakoll, P. J. (2008). Differences in daily energy expenditure in lean and obese women: the role of posture allocation. Obesity (Silver Spring) 16, 34-39.

Khayat, Z. A., Patel, N., and Klip, A. (2002). Exercise- and insulinstimulated muscle glucose transport: distinct mechanisms of regulation. Can. J. Appl. Physiol. 27, 129-151.

King, D. S., Baldus, P. J., Sharp, R. L., Kesl, L. D., Feltmeyer, T. L., and Riddle, M. S. (1995). Time course for exercise-induced alterations in insulin action and glucose tolerance in middle-aged people. J. Appl. Physiol. 78, 17-22.

Koivisto, V., and Defronzo, R. (1984). Exercise in the treatment of type II diabetes. Acta Endocrinol. 262(Suppl.), 107-116.

Kreisman, S. H., Halter, J. B., Vranic, M., and Marliss, E. B. (2003). Combined infusion of epinephrine and norepinephrine during moderate exercise reproduces the glucoregulatory response of intense exercise. Diabetes 52, 1347-1354.

Larose, J., Sigal, R. J., Khandwala, F., Prud'homme, D., Boule, N. G., Kenny, G. P., Diabetes, A., and Resistance Exercise Trial Investigators. (2011). Associations between physical fitness and $\operatorname{HbA}(\mathrm{c})$ in type 2 diabetes mellitus. Diabetologia 54, 93-102.

Larsen, J. J., Dela, F., Madsbad, S., and Galbo, H. (1999). The effect of intense exercise on postprandial glucose homeostasis in type II diabetic patients. Diabetologia 42, 1282-1292. Levine, J. A., Lanningham-Foster, L. M., Mccrady, S. K., Krizan, A. C., Olson, L. R., Kane, P. H., Jensen, M. D., and Clark, M. M. (2005). Interindividual variation in posture allocation: possible role in human obesity. Science 307, 584-586.

Levine, J. A., Mccrady, S. K., Lanningham-Foster, L. M., Kane, P. H., Foster, R. C., and Manohar, C. U. (2008). The role of free-living daily walking in human weight gain and obesity. Diabetes 57, 548-554. 
Little, J. P., Gillen, J. B., Percival, M. E., Safdar, A., Tarnopolsky, M. A., Punthakee, Z., Jung, M. E., and Gibala, M. J. (2011). Low-volume highintensity interval training reduces hyperglycemia and increases muscle mitochondrial capacity in patients with type 2 diabetes. J. Appl. Physiol. 111, 1554-1560.

Loimaala, A., Groundstroem, K., Rinne, M., Nenonen, A., Huhtala, H., Parkkari, J., and Vuori, I. (2009). Effect of long-term endurance and strength training on metabolic control and arterial elasticity in patients with type 2 diabetes mellitus. Am. J. Cardiol. 103, 972-977.

Manders, R. J., van Dijk, J. W., and Van Loon, L. J. (2010). Low-intensity exercise reduces the prevalence of hyperglycemia in type 2 diabetes. Med. Sci. Sports Exerc. 42, 219-225.

Marcus, R. L., Smith, S., Morrell, G., Addison, O., Dibble, L. E., WahoffStice, D., and Lastayo, P. C. (2008). Comparison of combined aerobic and high-force eccentric resistance exercise with aerobic exercise only for people with type 2 diabetes mellitus. Phys. Ther. 88, 1345-1354.

Marliss, E. B., and Vranic, M. (2002). Intense exercise has unique effects on both insulin releas e and its roles in glucoregulation: implications for diabetes. Diabetes 51(Suppl. 1), S271S283.

McBride, P. E., Einerson, J. A., Grant, H., Sargent, C., Underbakke, G., Vitcenda, M., Zeller, L., and Stein, J. H. (2008). Putting the diabetes prevention program into practice: a program for weight loss and cardiovascular risk reduction for patients with metabolic syndrome or type 2 diabetes mellitus. J. Nutr. Health Aging 12, 745s-749s.

Mikus, C. R., Oberlin, D. J., Libla, J. L., Taylor, A. M., Booth, F. W., and Thyfault, J. P. (2012). Lowering physical activity impairs glycemic control in healthy volunteers. Med. Sci. Sports Exerc. 44, 225-231.

Minuk, H. L., Vranic, M., Hanna, A. K., Albisser, A. M., and Zinman, B. (1981). Glucoregulatory and metabolic response to exercise in obese noninsulin-dependent diabetes. Am. J. Physiol. 240, E458-E464.

Moreira, S. R., Simoes, G. C., Moraes, J. F., Motta, D. F., Campbell, C. S., and Simoes, H. G.
(2011). Blood glucose control for individuals with type- 2 diabetes: acute effects of resistance exercise of lower cardiovascular-metabolic stress. J. Strength Cond. Res. doi: 10.1519/JSC.0b013e318242a609 [Epub ahead of print].

Morrison, S., Colberg, S. R., Mariano, M., Parson, H. K., and Vinik, A. I. (2010). Balance training reduces falls risk in older individuals with type 2 diabetes. Diabetes Care 33, 748-750.

Morrison, S., Colberg, S. R., Parson, H. K., and Vinik, A. I. (2012). Relation between risk of falling and postural sway complexity in diabetes. Gait Posture 35, 662-668.

Nelson, M. E., Rejeski, W. J., Blair, S. N., Duncan, P. W., Judge, J. O., King, A. C., Macera, C. A., and CastanedaSceppa, C. (2007). Physical activity and public health in older adults: recommendation from the American College of Sports Medicine and the American Heart Association. Med. Sci. Sports Exerc. 39, 1435-1445.

O'Gorman, D. J., Karlsson, H. K., Mcquaid, S., Yousif, O., Rahman, Y., Gasparro, D., Glund, S., Chibalin, A. V., Zierath, J. R., and Nolan, J. J. (2006). Exercise training increases insulin-stimulated glucose disposal and GLUT4 (SLC2A4) protein content in patients with type 2 diabetes. Diabetologia 49, 2983-2992.

Physical Activity Guidelines Advisory Committee. (2008). Physical Activity Guidelines Advisory Committee Report, 2008. Washington, DC: U.S. Department of Health and Human Services.

Ploug, T., Galbo, H., and Richter, E. A. (1984). Increased muscle glucose uptake during contractions: no need for insulin. Am. J. Physiol. 247, E726-E731.

Poehlman, E. T., Dvorak, R. V., Denino, W. F., Brochu, M., and Ades, P. A. (2000). Effects of resistance training and endurance training on insulin sensitivity in nonobese, young women: a controlled randomized trial. J. Clin. Endocrinol. Metab. 85, 2463-2468.

Richter, E. A., Garetto, L. P., Goodman, M. N., and Ruderman, N. B. (1982). Muscle glucose metabolism following exercise in the rat: increased sensitivity to insulin. J. Clin. Invest. 69, 785-793.
Richter, E. A., Ploug, T., and Galbo, H. (1985). Increased muscle glucose uptake after exercise. No need for insulin during exercise. Diabetes 34 , 1041-1048.

Sigal, R. J., Kenny, G. P., Boulé, N. G., Wells, G. A., Prud'homme, D., Fortier, M., Reid, R. D., Tulloch, H., Coyle, D., Phillips, P., Jennings, A., and Jaffey, J. (2007). Effects of aerobic training, resistance training, or both on glycemic control in type 2 diabetes: a randomized trial. Ann. Intern. Med. 147, 357-369.

Snowling, N. J., and Hopkins, W. G. (2006). Effects of different modes of exercise training on glucose control and risk factors for complications in type 2 diabetic patients: a metaanalysis. Diabetes Care 29, 25182527.

Swartz, A. M., Squires, L., and Strath, S. J. (2011). Energy expenditure of interruptions to sedentary behavior. Int. J. Behav. Nutr. Phys. Act 8, 69.

Thomas, D. E., Elliott, E. J., and Naughton, G. A. (2006). Exercise for type 2 diabetes mellitus. Cochrane Database Syst. Rev. 3, CD002968.

Umpierre, D., Ribeiro, P. A., Kramer, C. K., Leitao, C. B., Zucatti, A. T., Azevedo, M. J., Gross, J. L., Ribeiro, J. P., and Schaan, B. D. (2011). Physical activity advice only or structured exercise training and association with HbAlc levels in type 2 diabetes: a systematic review and meta-analysis. JAMA 305, 1790-1799.

van Dijk, J. W., Manders, R. J., Hartgens, F., Stehouwer, C. D., Praet, S. F., and Van Loon, L. J. (2011). Postprandial hyperglycemia is highly prevalent throughout the day in type 2 diabetes patients. Diabetes Res. Clin. Pract. 93, 31-37.

van Dijk, J. W., Manders, R. J., Tummers, K., Bonomi, A. G., Stehouwer, C. D., Hartgens, F., and Van Loon, L. J. (2012a). Both resistance- and endurance-type exercise reduce the prevalence of hyperglycaemia in individuals with impaired glucose tolerance and in insulin-treated and non-insulin-treated type 2 diabetic patients. Diabetologia 55, 1273-1282. van Dijk, J. W., Tummers, K., Stehouwer, C. D., Hartgens, F., and Van Loon, L. J. (2012b). Exercise therapy in type 2 diabetes: is daily exercise required to optimize glycemic control? Diabetes Care 35, 948-954.
Vincent, K. R., Braith, R. W., Feldman, R. A., Magyari, P. M., Cutler, R. B. Persin, S. A., Lennon, S. L., Gabr, A. H., and Lowenthal, D. T. (2002). Resistance exercise and physical performance in adults aged 60 to 83 . $J$. Am. Geriatr. Soc. 50, 1100-1107.

Willey, K. A., and Singh, M. A. (2003). Battling insulin resistance in elderly obese people with type 2 diabetes: bring on the heavy weights. Diabetes Care 26, 1580-1588.

Zhao, G., Ford, E. S., Li, C., and Mokdad, A. H. (2008). Compliance with physical activity recommendations in US adults with diabetes. Diabet. Med. 25, 221-227.

Zierath, J. R., He, L., Guma, A., Odegoard Wahlstrom, E., Klip, A., and Wallberg-Henriksson, H. (1996). Insulin action on glucose transport and plasma membrane GLUT4 content in skeletal muscle from patients with NIDDM. Diabetologia 39, 1180 1189.

Zijlstra, G. A., Van Haastregt, J. C., Van Rossum, E., Van Eijk, J. T., Yardley, L., and Kempen, G. I. (2007). Interventions to reduce fear of falling in community-living older people: a systematic review. J. Am. Geriatr. Soc. 55, 603-615.

Conflict of Interest Statement: The author declares that the research was conducted in the absence of any commercial or financial relationships that could be construed as a potential conflict of interest.

Received: 03 April 2012; paper pending published: 20 April 2012; accepted: 02 May 2012; published online: 17 May 2012.

Citation: Colberg SR (2012) Physical activity: the forgotten tool for type 2 diabetes management. Front. Endocrin. 3:70. doi: 10.3389/fendo.2012.00070 This article was submitted to Frontiers in Diabetes, a specialty of Frontiers in Endocrinology.

Copyright (c) 2012 Colberg. This is an open-access article distributed under the terms of the Creative Commons Attribution Non Commercial License, which permits non-commercial use, distribution, and reproduction in other forums, provided the original authors and source are credited. 